\title{
Bali Tourism Destination Structural Loyalty Model from Consumer Behavior Perspective
}

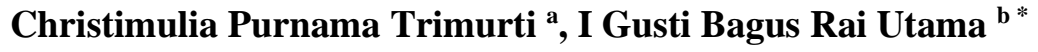

${ }^{a}$ Management Study Program, Dhyana Pura University, Bali (https://orcid.org/0000-0003-0517-5355)

${ }^{b}$ Hospitality Management Study Program, Dhyana Pura University, Bali (https://orcid.org/0000-0002-1962-0707)

* Corresponding Email: raiutama@undhirabali.ac.id

Article History: Received:11 January 2021; Accepted: 27 February 2021; Published online: 5 April 2021

Abstract: This research is confirmatory research of the destination development model from the perspective of travel motivation which is expected to be used as a theoretical reference model of a tourism marketing mix specifically related to travel motivation, destination image, tourist satisfaction, and tourist loyalty. This research uses a quantitative approach to analyze the direct relationship between the variables that exist in the model. The number of respondents was determined based on the accidental ideal sample size of the SEM-AMOS structural analysis tool around 413 respondents for the domestic tourists and foreign tourists. The conclusion is tourist expectation has a positive and significant effect on destination attractiveness. Destination attractiveness has a positive and significant effect on destination image. Destination image has a positive and significant effect on tourist satisfaction. Tourist satisfaction has a positive and significant effect on tourist loyalty. The implications of this research are maintaining the tourist satisfaction with the existing tourist attractions and their experiences. They are also satisfied with the availability of facilities and services during a vacation in Bali.

Keywords: expectation, motivation, attractiveness, image, satisfaction, loyalty.

\section{Introduction}

Several times, Bali tourism destinations have been declared the best destination in the world by observing tourism agencies. However, some tourists who have visited Bali, not all come back to vacation in Bali again (Astuti, et al 2019). This fact shows that measuring the loyalty of tourists is very important to do to know the factors that cause them to come back (revisit). Confirmation of the model of tourist loyalty to the fact of returning tourists that have been developed by several previous researchers such as Tze and Wang (2012), Wilson, et al. 2012; Zhang, et al 2014; Lin and Liu, 2018).

This research is confirmatory research of the destination development model from the perspective of travel motivation which is expected to be used as a theoretical reference model of a tourism marketing mix specifically related to travel motivation, destination image, tourist satisfaction, and tourist loyalty. The results of this study are expected to determine: (1) the dynamics of the marketing mix of tourism destinations based on the perspective of foreign and domestic tourists in Bali as a material for consideration to improve quality destination. (2) The determinants of tourist satisfaction in Bali as preliminary information on destination management that are in line with tourist expectations. (3) The confirmation of tourist loyalty to visit Bali destinations. (4) The exploration of tourist loyalty factors as information to improve the quality of tourism destinations.

This research is also expected to provide a different perspective about marketing theory and at the same time be a useful marketing theory for all parties who want to understand tourism marketing such as tourism students, tourism business managers, and other governments who are interested in developing the tourism sector.

This research is feasible to be carried out because there are still many differences in the components of the destination image. For example, Cherifi, et al (2014) assume that destination images consist only of cognitive components, whereas cognitive perception or evaluation only refers to an individual's knowledge and belief in an object that is perceived or evaluated. Whereas Stylos, et al (2016) assume that consumers build a total image is based on the evaluation of various attributes of products and services. Likewise, Rajesh, (2013) states that tourist perceptions of various destination attributes will interact in forming a total image. However, Chen, (2011) has tested based on empirical facts that there is a relationship between cognitive attributes with a total image and concluded that the total impression is highly dependent on destination attributes based on individual tourist perceptions. 
This study confirms five dimensions or variables in the tourist loyalty model. The five dimensions are (1) tourist expectations, (2) destination attractiveness, (3) destination image, (4) tourist satisfaction, and (5) tourist loyalty can be examined using the consumer loyalty theory approach.

\section{Literature Review}

\subsection{Tourism destination image}

To get a better understanding of destination image, $\mathrm{Li}$, et al (2014) have stated a theoretical framework about destination image built on four terms, namely complex, multi-element and process, relative, and dynamic. The destination image is something complex to explain in an analytical dimension. Multi elements and processes explain the destination image as a dimension of the results of an action. Relatively, a destination image is also a strategic tool, especially in the management and marketing objectives. While dynamically, the destination image always follows the policy based on the image of a destination.

Destination image becomes complex because there is still a lot of debate over how to measure it, and the many components that are included in the measurement. The multi-dimensions of the destination image are also caused by the attributes that are included are quite diverse and interrelated. While its relativity is caused by the subjective way of interpreting it from one another and very much depends on the comparison to be used. Destination image is also not static but very dynamic along with changes in space, time, and place. Based on this reason the destination image variable is included in the loyalty model, because Bali's tourism destination image might have changed compared to the past (Utama, 2015; Utama, 2016; Trimurti and Utama, 2020).

The destination attributes above affect the image of the destination as a result of the subjective perception of tourists which influences the tourist destination's choice of tourism. Destination image influences the process of selecting tourist destinations in the future as a consequence of evaluations that have been carried out (Cherifi, et al 2014; Stylos, et al 2016; Rajesh, 2013; Chen, 2011). The test model conducted by Wu, (2016) implies that the key elements of destination loyalty (repeat visits and recommending potential tourists) are determined by the destination's image through total satisfaction. In the research to be carried out, assume that the destination image affects tourist satisfaction and will influence tourist loyalty.

\subsection{Tourist satisfaction}

In the marketing term, satisfaction plays an important role in the marketing planning of products and services as well. Related to the tourism term, tourist satisfaction is important for the success of marketing tourism destinations because satisfaction is directly affecting the decision of tourists to enjoy products and services, and the decision to come back is also influenced by tourist satisfaction (Lee, et al 2011).

In the context of modern marketing, customer satisfaction has become the main pillar in running a business to realize the company's goals in making a profit. Consumers who are satisfied by the company become a big asset to the survival of the company. Therefore, it is necessary to do the management of the quality of services offered to meet customer satisfaction. Well-managed service quality will give good results to meet customer satisfaction (Utama, 2014; Kotler, et al 2019).

Consumers have the freedom to judge whether the mix of services offered by the company provides satisfaction as they want or not. If the service they feel is unsatisfactory, it is feared that they will tell others, so that it will adversely affect the development of service provider companies. And vice versa if the service is satisfactory according to customers what they want, it will benefit the service provider companies, because the cost of promotion and effort to introduce company products will be reduced. To encourage the achievement of the service marketing mix goal, companies need to provide additional services (supplementary services) for core service transactions so that these core services can provide satisfaction, these additional services can be reflected in the service mix elements offered by service companies to consumers (Utama, 2014; Trimurti and Utama, 2020).

According to Chernev, (2020), each service provided to customers needs to be evaluated by measuring the level of service quality that the company has provided to customers so that it can be known to what extent the quality of service provided has been able to provide satisfaction to customers. Furthermore, Ahmed and Rahman, (2015). states that there are four elements in consumer satisfaction, namely: (1) the element of expectation, where consumers' 
expectations of an item or service have been formed before consumers buy goods or services. At the time of the purchase process, consumers expect that the goods or services they receive are following expectations according to their wishes and beliefs. Goods or services following consumer expectations will cause consumers to be satisfied. (2) Performance element, where the actual performance of goods or services when used is not affected by consumer expectations. When the actual performance of goods or services is successful, then consumers will feel satisfied. (3) Elements of comparison, where this is done by comparing the performance expectations of goods or services before buying with the perception of the actual performance of the goods or services. Consumers will feel satisfied when expectations before the purchase match or exceed consumer perceptions of the actual performance of the product; (4) elements of experience, where consumer expectations are influenced by their experience of the use of brands of goods or services that are different from others. From several of the opinions, we found a common meaning that customer satisfaction is an assessment of customers for the use of goods or services based on expectations and reality. In other terms, if consumers feel that what they are getting is lower than expected then the consumer will not be satisfied. Conversely, if consumers get more than what they expect, consumers will be satisfied. Whereas in a situation where what is received is the same as expected, then the consumer will feel neutral.

Trimurti and Utama (2020) found the theory of the goodness of fit that tourist satisfaction is based on how well or following the expectations of tourists towards a tourism destination. The suitability of tourist expectations can only be measured if they have experienced or enjoyed a product or service at a destination they visited. A comparison of the image of a destination before they visit compared with the reality they see feels, and experience will determine the degree of tourist satisfaction,

Inequity theory, customer satisfaction can be seen as a relationship between the money they spend (costs) to get a product or service with the benefits they get (benefits). Equity theory is also developed and used by (Shah, 2014) to measure consumer satisfaction, where money, benefits, time, and effort done by consumers determine satisfaction. The theory developed by Heskett was later known as The service profit chain (Utama, 2017).

In the tourism context, norm theory and ideal standard theory uses comparison standards, where consumers compare products or services with products or services they have bought or enjoyed before. Tourists can compare with similar products or services on the destinations they have experienced, before determining the choice of the next destination. The results of this comparison can determine the satisfaction or dissatisfaction of tourists (Chi, et al 2020).

The next theory is a perceived performance model developed by Park, et al (2019). state that consumer dissatisfaction is only related to a function or usefulness of the actual appearance of a product or service based on various expectations about the function and usefulness of products and services. This theory emphasizes that the actual appearance of a product and the expectations of consumers must stand alone, not based on a comparison of the actual appearance of the product with experience. This theory believes that the actual poor performance of the past at different destinations may have changed for the better and has been in line with the current expectations of consumers on new destinations. In this theory of perceived performance, a measurement of tourist satisfaction will be effective if tourists do not know about what they will enjoy or do, and tourists have never traveled to the destinations they visit today.

Although many measurements can be used to measure consumer satisfaction, the core meaning of tourist satisfaction must remain the basic measurement used to evaluate the appearance of tourism destination products and services (Prebensen, et al 2013). Measuring tourist satisfaction will be important especially concerning destination selection, products to be consumed by tourists, and at the same time knowing to repurchase. Measuring tourist satisfaction is also to evaluate the current destination. The results of evaluations of destinations are indicators that can help destination marketers make adjustments or changes to improve the quality of destination products that are more in line with consumer expectations.

Several methods can be used to measure customer satisfaction, and measuring satisfaction is an important action to see customer loyalty (Armstrong, et al 2014), knowing consumer responses to products (Wilson, et al., 2012), knowing consumer expectations, knowing product performance, knowing dynamics of consumer tastes, and at the same time determine the direction of product innovation following consumer expectations (Stewart, 2015) and explicitly Buchanan-Oliver, and Fitzgerald, 2016) says that measuring customer satisfaction is essentially evaluating the product and consumer expectations.

According to Arli, et al (2018). The method used to measure consumer satisfaction can be done by (1) measurement carried out directly with questions. (2) respondents are asked questions about how much they expect a certain attribute and how much they feel. (3) respondents are asked to write down the problems they face relating to 
the offer from the company and also asked to write down the problems they face related to the offer from the company and also asked to write down the improvements they suggest. and other methods, (4) respondents can be asked to rank various elements of the offer based on the degree of importance of each element and how well the company is performing in each element.

According to Tze and Wang (2012), tourist satisfaction with tourism destinations is a multidimensional concept consisting of many interrelated factors. One factor that makes tourists satisfied; maybe other factors are not able to satisfy tourists. According to him, the aspect of the destination that consists of attractions, amenities, and accessibility may have similarities between the destinations; however, for the aspect of the enlightenment, in this case, the intangible services are very dynamic and tend to demand quality that is increasing from time to time. The model developed by Tze and Wang (2012) explains that satisfaction is a mediating variable of multi variables in the form of the attractiveness of destinations, services, and value for money towards the formation of tourist loyalty. Tourist satisfaction is a measurement carried out simultaneously (overall satisfaction) because tourism itself is an integrated product and has a link between all the satisfying factors. Multi Variables that make up total satisfaction are a combination of variable tourist attractions, hotels or accommodation, immigration services, restaurants, shopping centers, and transportation.

Meanwhile, according to Prebensen, et al (2013), one of the crucial elements of successful destination marketing is tourist satisfaction, which influences the choice of destination and the decision to return. It implies that a key element of loyalty to a destination (repeat visits and recommending potential tourists) is determined by tourist satisfaction.

\subsection{Tourist loyalty}

In general, tourist loyalty can be measured by various approaches, namely (1) the behavioral approach, (2) the attitudinal approach, and (3) the composite approach (Prebensen, et al 2013). The behavioral approach is related to consumer loyalty to the brand which is indicated by the willingness to make purchases, determine the number of purchases, and the opportunity to make repeat purchases (Tabaku and Zerellari, 2015). It has received much debate, especially regarding the weakness of the measurement approach which assumes that this approach will apply if the production process is static while the production process continues to experience dynamics. This loyalty measurement cannot explain what factors have an impact on tourist loyalty. The loyalty of tourists to destinations or tourism products may not be enough to explain why and how tourists make repeat visits or recommend friends, family, or others as potential tourists.

Another approach is the attitudinal approach. Measurement of satisfaction with this approach emphasizes the brand as a choice for consumers or the willingness to make a purchase. Loyal consumers are shown by a deeper willingness to express psychological loyalty that ultimately gives birth to a commitment or statement to choose. Tourists may have a favorable attitude towards the destination, and they express it intending to return. This loyalty measures the love of tourists/consumers for the product and explains the more willingness of tourists towards destinations such as the willingness and ability to pay more (Lin and Liu, 2018).

The third approach is the composite or combination approach. This approach is a combination of behavioral approaches and attitudinal approaches (Lin and Liu, 2018). It was explained that consumers who buy are consumers who have loyalty to the brand and they should have a positive attitude towards the product. Unfortunately, this approach has limitations, that not all weights or scores can be calculated and apply to both behavioral and attitude factors, because the two factors may have different measurements. Some researchers even suggest choosing one of these two approaches or integrating the two, Thus, a theoretical study shows that understanding consumer/tourist loyalty needs to consider motivational factors and satisfaction together (Della Corte, et al 2015).

Zhang, et al (2014) explained that the benefits that can arise from customer loyalty for the company are: (1) consumers who are satisfied with the goods and services they consume will tend to repurchase from the same producer. (2) Satisfaction is a factor that encourages positive word of mouth communication. (3) The effect of customer satisfaction on the behavior of satisfied consumers tends to consider service providers who can satisfy as the first consideration if they want to buy the same product or service.

Wilson, et al (2012) also believe that loyalty is voluntary consumer loyalty which is assumed to be in the market mechanism, which can be seen from the actions of consumers in several ways, namely: (1) willingness to tell satisfaction of a product to friends, relatives, or other people who might become potential new customers for the company. (2) Willingness to repurchase or repurchase. (3) Directing other potential customers to make purchases on the same product. (4) It gives a positive value to the company. (5) Harmonious social relations with companies. (6) 
Willingly involved directly with the company to improve product quality. Loyal customers can have a positive effect on the company because loyal customers will be good marketers for the company through testimonies about the company. They also tend to re-purchase the same products and brands. They also tend to direct other prospective buyers to buy products that are currently being enjoyed.

Contextualization of tourist loyalty to tourism destinations is loyalty is the consistency of tourists to always visit a destination even though competitors offer new destinations with superior quality attributes. In the tourism industry, there is empirical evidence that considers satisfaction is a strong indicator of tourist loyalty to return to a tourism destination, and at the same time loyal tourists will be good marketers for destinations because they tend to tell stories and recommend friends, family, and relatives, and others to visit the destinations they have visited (Zhang, et al 2014). The satisfied tourists will tend to come back to the same destination during the upcoming holidays and tend to share positive stories about their experiences during the holidays with friends and relatives. According to him, this trend is a reliable indicator of measuring tourist loyalty. Furthermore, it is said that satisfaction has an impact on tourist loyalty and will be an indicator of loyalty to all industries in a destination.

In a study of tourist loyalty, Zhang, et al (2014) succeeded in building a tourist loyalty model as a series of interrelated and originated from the destination image in the minds of tourists, destination image associated with the attributes of a destination and the total impact on tourist satisfaction simultaneously. According to him, the total satisfaction of tourists has an impact on loyalty to the destination. It is indeed very difficult to measure tourist loyalty to a destination, but a commitment to return to a destination is an appropriate indicator to measure tourist loyalty.

But according to Wilson, et al (2012) the motivation of travel affects the image of the destination, while the image of the destination also affects tourist satisfaction, where tourist satisfaction is a determinant of tourist loyalty. Tourist satisfaction is also a connecting variable between tourist travel motivation and tourist loyalty. Whereas tourist loyalty to destinations is only evidently shown by the variables: (1) commitment to revisit the destination on the upcoming holidays, and (2) willingly volunteering to direct potential tourists to travel to the destinations they have visited.

\subsection{Research Hypothesis}

The hypothesis is built from a theoretical model of tourist behavior in travel decision making (Wilson, et al 2012; Zhang, et al 2014; Lin and Liu, 2018) namely:

1) There is a positive correlation between tourist expectation (X1) and destination attraction (Y1)

2) There is a positive correlation between destination attraction (Y1) and the destination image (Y2)

3) There is a positive correlation between destination image (Y2) and tourist satisfaction (Y3)

4) There is a positive correlation between tourist satisfaction (Y3) and tourist loyalty (Y4)

\section{Research Methods}

This research uses a quantitative approach to analyze the direct relationship between the variables that exist in the model, namely the variable expectations of travel, destination image, tourist satisfaction, and tourist loyalty.

The population in this study was tourists who were on vacation in Bali. The sample was chosen based on an accidental sampling technique, which is a sampling technique based on the provisions of tourists who happen to be on vacation in Bali. The number of respondents was determined based on the accidental with an ideal sample size of the SEM-AMOS structural analysis tool around 413 respondents for the category of domestic tourists and foreign tourists (Utama and Mahadewi, 2012).

The research instrument in this study was a research questionnaire. The research questionnaire in question is the things that researchers must ask and answers that should be obtained from respondents based on their respective perceptions of Bali as a tourist destination. This research is confirmation research of tourism destination marketing mix from the perspective of traveling motivation theory. This research consists of five dimensions or variable study objects which are formed into a tourist loyalty model. Based on the five variables, namely tourist expectations $\left(\mathrm{X}_{1}\right)$, destination attractiveness $\left(\mathrm{Y}_{1}\right)$, destination image $\left(\mathrm{Y}_{2}\right)$, tourist satisfaction $\left(\mathrm{Y}_{3}\right)$, and tourist loyalty $\left(\mathrm{Y}_{4}\right)$ can be examined or tested using a theoretical approach to consumer loyalty. Research on the five variables mentioned above is not a separate study with each other, but causality research that is integrated with the tested constructs (Wilson, et al 2012; Zhang, et al 2014; Lin and Liu, 2018)

The loyalty model conducted by Zhang, et al 2014) only included three latent variables namely internal motivation, external motivation, and tourist satisfaction. The model does not include destination image variables, whereas in tourism these variables are proven to be closely and strongly related to tourists' decision to determine destination choices in the research conducted by Utama, et al., (2012) and Zhang, et al 2014. Loyalty model testing 
done by Zhang, et al (2014) did not include tourist motivation variables and only included destination image variables, destination attributes, and tourist satisfaction. Testing the motivation variable as a determining variable in the formation of destination loyalty is an important test because the decision to be moved and attracting tourists to travel is determined by these variables (Wilson, et al 2012; Zhang, et al 2014; Lin and Liu, 2018).

The statistical description is an analysis carried out by describing a collection of data visually, which can be done by description with numerical tables, text, and figures. The survey was conducted and several data obtained, then testing the hypothesis using Structural Equation Modeling (SEM).

Crockett, (2012) suggested that covariance structure models can be used to test various complex models. Various tourist loyalty research models also use SEM as a model test tool, as in the research of Wilson, et al (2012); Zhang, et al (2014). SEM is a statistical model that explains the relationships among several variables, by examining the structure of the relationships among the variables in the model (Hair, et al., 2017).

\section{Results}

\subsection{Respondent Profile}

The number of respondents was 413 people consisting of $56.66 \%$ involving male and $43.34 \%$ women. When viewed from their nationality, $40.68 \%$ of them are Australian and the rest are other nationalities such as the Netherlands, German, USA, Japan, France, Italy, England, Switzerland, and Others. Respondents in this study were predominantly repeated tourists at $79.90 \%$, and only $20.10 \%$ made their first visit to Bali (See Table 1).

Table 1 Profile of Respondent

\begin{tabular}{clcc}
\hline Profile & Category & Frequency & Percent \\
\hline Sex & Male & 234 & $56.66 \%$ \\
& Female & 179 & $43.34 \%$ \\
\hline Nationality & Australian & 168 & $40.68 \%$ \\
& Netherlands & 41 & $9.93 \%$ \\
& German & 27 & $6.54 \%$ \\
& USA & 24 & $5.81 \%$ \\
& Japan & 17 & $4.12 \%$ \\
& France & 17 & $4.12 \%$ \\
& Italy & 15 & $3.63 \%$ \\
& England & 15 & $3.63 \%$ \\
& Switzerland & 13 & $3.15 \%$ \\
& Indonesian & 76 & $18.40 \%$ \\
\hline visit & More than two times & 263 & $63.68 \%$ \\
& Two times & 67 & $16.22 \%$ \\
& First time & 83 & $20.10 \%$ \\
\hline
\end{tabular}

\subsection{Description tourist expectation}

Expectations they traveled the most strongly encouraged the motive of finding something beautiful and unique. The next expectation is to expect culinary adventure, expect local people interaction, expect cultural events, expect high-quality public transportation, and expect the high quality of infrastructure. Other expectations are to expect tropical climate and weather conditions and expect shopping destination adventure (see Table 2).

Table 2 Mean of Tourist Expectation

\begin{tabular}{lrcl}
\hline Indicator & Mean & Std. Deviation & Remark \\
\hline Expect beautiful and Unique Attractions & 4.34 & 0.860 & Very Good \\
Expect culinary adventure & 4.13 & 0.911 & Good \\
Expect local people interaction & 4.11 & 0.880 & Good \\
Expect cultural events & 4.06 & 0.982 & Good
\end{tabular}


Expect highly quality public transportation

Expect the high quality of infrastructure

Expect tropical climate and weather condition

Expect shopping destination adventure

Valid N (listwise) $=413$

$\begin{array}{lll}3.98 & 1.009 & \text { Good } \\ 3.55 & 1.077 & \text { Good } \\ 3.37 & 1.376 & \text { Moderate } \\ 3.26 & 1.191 & \text { Moderate }\end{array}$

Remarks: $(1.00-1.80=$ Very bad $),(1.81-2.60=$ bad $),(2.61-3.40=$ Moderate $),(3.41-4.20=$ Good $),(4.21-5.00=$ Very Good)

\subsection{Description of the Destination Attractiveness}

The attractiveness of the destination, the most powerful thing that motivates tourists to travel to Bali is an interest in Balinese culture, the natural beauty of Bali, history related to Bali. The second factor is the attractiveness of the leisure time in the destination, the events and festivals in destination, the various types of food and beverage in destination, the prices in destination, the facilities and services for hotels in a destination, the proximity from the country of origin, and the security of the destination. While the third attraction factor is the transportation has grown in destination, the health-supporting facilities in dstination, the services of qualified tour guides, the quality travel agency services, and the comfort and service of immigration procedures (See Table 3).

Table 3. Mean of Destination Attractions

\begin{tabular}{lrcl}
\hline Indicator & Mean & Std. Deviation & Remark \\
\hline The culture of a destination & 4.36 & 0.814 & Very Good \\
The nature of a destination & 4.31 & 0.881 & Very Good \\
The history of a destination & 4.25 & 0.873 & Very Good \\
The leisure time in a destination & 4.15 & 0.841 & Good \\
The events and festivals in the destination & 3.98 & 0.985 & Good \\
The various types of food and beverage in the destination & 3.98 & 0.987 & Good \\
The prices in destination & 3.82 & 1.077 & Good \\
The facilities and services for hotels in a destination & 3.70 & 1.036 & Good \\
The proximity from the country of origin & 3.69 & 1.112 & Good \\
The security of the destination & 3.41 & 1.239 & Good \\
The transportation has grown in destination & 3.38 & 1.142 & Moderate \\
The health-supporting facilities in the destination & 3.35 & 1.162 & Moderate \\
The services of qualified tour guides & 3.35 & 1.153 & Moderate \\
The quality travel agency services & 3.24 & 1.147 & Moderate \\
The comfort and service of immigration procedures & 3.07 & 1.292 & Moderate \\
\hline
\end{tabular}

Valid N (listwise) $=413$

Remarks: $(1.00-1.80=$ Very bad $),(1.81-2.60=$ bad $),(2.61-3.40=$ Moderate $),(3.41-4.20=$ Good $),(4.21-$ $5.00=$ Very Good)

\subsection{Description of Destination Image}

Until now, Bali tourism destinations still have a very good image as a destination that has a unique culture, history, and art. Another good image is that Bali is also a destination that has a Balinese image that has a good social environment, a Balinese image is good for leisure and recreation activities, a Balinese image has a good tourist infrastructure, a Balinese image has a good atmosphere, a Balinese image has a good natural environment, and image Bali has stable political conditions and good economic factors (See Table 4).

Table 4 Mean of Destination Images

\begin{tabular}{lrrl}
\hline Destination Images & Mean & Std. Deviation & Remark \\
\hline Image Bali has a unique culture, history, and art & 4.31 & 0.778 & Very Good \\
Image Bali has a good social environment & 4.14 & 0.898 & Good \\
Image Bali is good for leisure and recreation activities & 4.13 & 0.922 & Good
\end{tabular}


Image Bali has a good tourist Infrastructures

Image Bali has a good atmosphere

Image Bali has a good natural environment

Image Bali has stable political conditions and good economic factors

Valid N (listwise) $=413$

Remarks: $(1.00-1.80=$ Very bad $),(1.81-2.60=$ bad $),(2.61-3.40=$ Moderate $),(3.41-4.20=$ Good $),(4.21-$

\subsection{Description of tourist Satisfaction}

Regarding tourist satisfaction, several attributes were found to be following tourists' expectations when they traveled to Bali. They are very satisfied with the existing tourist attractions and satisfied with the trip to Bali. Some are also satisfied with the availability of facilities and are satisfied with services during a vacation in Bali (See Table $5)$.

Table 5 Mean of Tourist Satisfaction

\begin{tabular}{lccl}
\hline Tourist Satisfaction & Mean & Std. Deviation & Remark \\
\hline Satisfied with the existing tourist Attractions & 4.22 & 0.780 & Very Good \\
Satisfied with the trip to Bali & 4.25 & 0.795 & Very Good \\
Satisfied with the availability of the facilities & 4.11 & 0.817 & Good \\
Satisfied with the services during a vacation in Bali & 4.16 & 0.814 & Good \\
Valid N (listwise) $=413$ & \\
Remarks: $(1.00-1.80=$ Very bad), $(1.81-2.60=$ bad), (2.61-3.40= Moderate), $(3.41-4.20=$ Good) $),(4.21$ - \\
$5.00=$ Very Good)
\end{tabular}

\subsection{Description of Tourist Loyalty}

At the end of the survey session, respondents were asked if they would return on their next tour and they answered that they would come again to Bali, and also recommend their family and friends to travel to Bali (See Table 6).

Table 6 Tourist Loyalty

\begin{tabular}{lrcl}
\hline Tourist Loyalty & \multicolumn{1}{c}{ Mean } & Std. Deviation & Remark \\
\hline Revisit Intention & 4.38 & 0.778 & Very Good \\
Recommend others & 4.39 & 0.767 & Very Good \\
\hline
\end{tabular}

Valid N (listwise) $=413$

Remarks: $(1.00-1.80=$ Very bad $),(1.81-2.60=$ bad $),(2.61-3.40=$ Moderate $),(3.41-4.20=$ Good $),(4.21-$ $5.00=$ Very Good)

\subsection{Tourist Behavior Destination Model}

The testing theoretically produces models that meet the criteria for the goodness of fit. The results of the confirmatory factor analysis that have met the suitability criteria of this model indicate that the researcher's assumptions regarding the suitability of the measurement model under study have been supported by observational data in the field. Of the several criteria to measure a model fit, namely RMSEA, GFI, AGFI, TLI, and CFI all indicate that the model can be said to be fit, requiring only minor modifications following the general rules in the analysis of structural models. Modifications can be made based on a priori concepts which assume that differences can occur between the initial concept and data in the field, this is following the statements of Hair, et al (2017) that primary research is never perfect, which causes differences between the results the topic is the same though. The results of testing theoretical models such in Figure 1. 


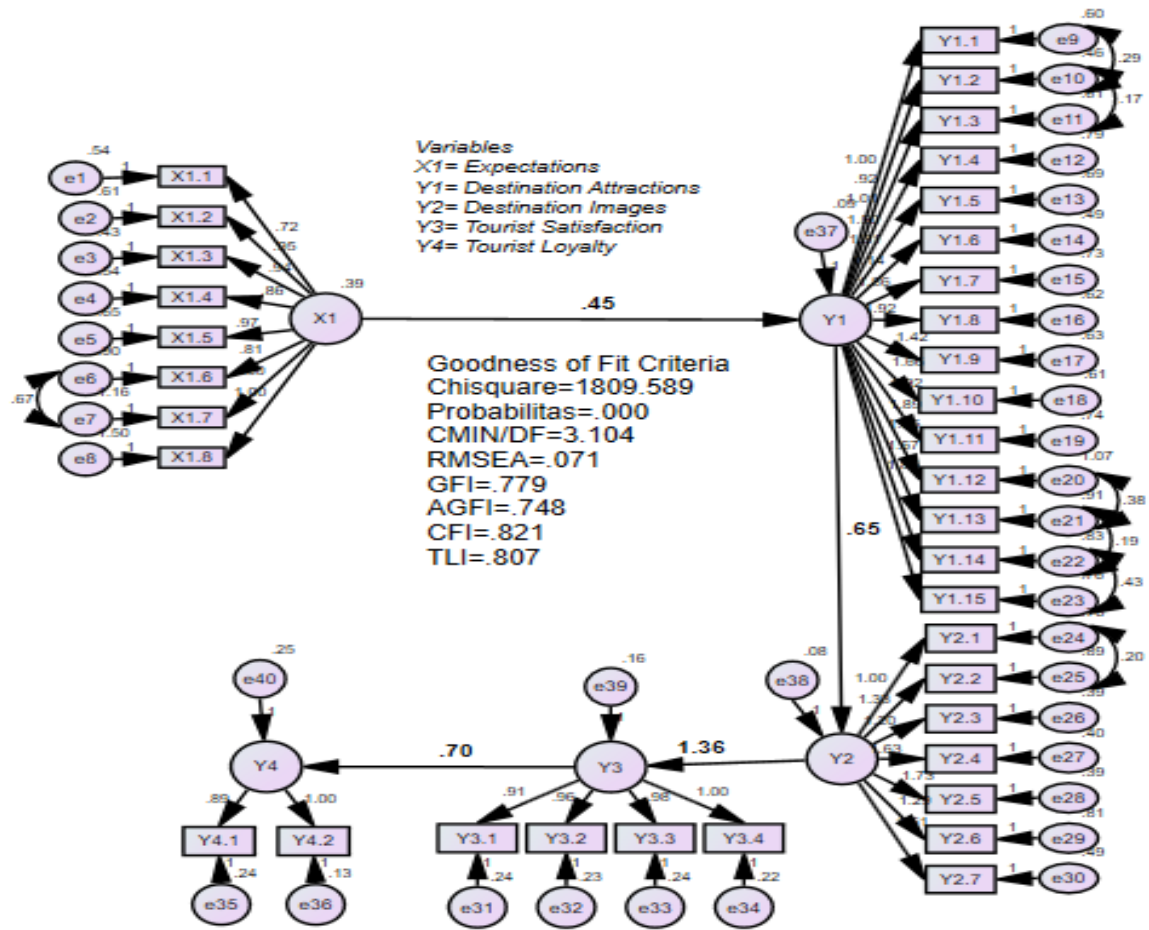

Figure 1. Bali Tourism Destination Structural Loyalty Model from Consumer Behavior Perspective Source: (Wilson, et al 2012; Zhang, et al 2014; Lin and Liu, 2018)

The construct of this study is a combination of two constructs (Wilson, et al 2012; Zhang, et al 2014; Lin and Liu, 2018) which have different latency, so overlapping research indicators are difficult to avoid. The chosen technique is to modify the indices of the indicators that are has a large MI (Modification Indices) Modification of indices is justified in the rules of the SEM structural model, as long as theoretically and conceptually, a pair of indicators is indeed possible overlapping (Hair, et al 2017). The results of the model testing can be seen in Table 7.

Table 7 the Goodness of Fit Index

\begin{tabular}{lccc}
\hline The goodness of Fit Index & Cut off Value & Result & Goodness of Fit \\
\hline $\mathrm{X}^{2}$-Chi-Square & Expected Small & 1809.589 & Fit \\
Significance Probability & $\geq 0.05$ & 0.000 & Not used for $\mathrm{n}>200$ \\
RMSEA & $\leq 0.08$ & 0.071 & Fit \\
GFI & $\geq 0.90$ & 0.779 & moderate \\
AGFI & $\geq 0.90$ & 0.748 & moderate \\
CMIN / DF & $\leq 3.00$ & 3.104 & moderate \\
TLI & $\geq 0.95$ & 0.821 & moderate \\
CFI & $\geq 0.95$ & 0.807 & moderate \\
\hline
\end{tabular}

Test results can be declared eligible by some of the criteria in Table 7, namely the criteria of RMSEA, GFI, AGFI, CMIN / DF, TLI, and CFI so that all hypotheses proposed in this study can be explained.

Table 8. Maximum Likelihood Estimates Regression Weights

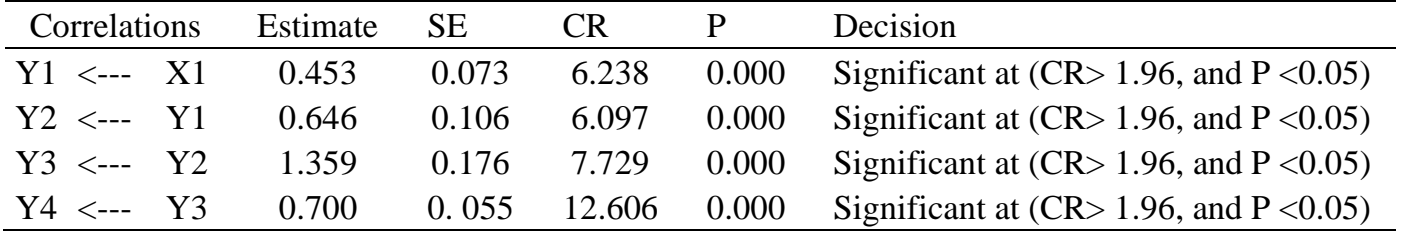


After all, assumptions can be fulfilled, and then hypothesis testing will be carried out as proposed in the previous chapter. Testing the four hypotheses of this research is carried out as shown in Table 8 . The results of the hypothesis test are as follows:

1. Variable expectation (X1) has a positive and significant effect on the destination attractiveness (Y1) as evidenced by the results of the Critical Ratio test $(6,238>1.96)$.

2. The destination attractiveness variable (Y1) has a positive and significant effect on destination image (Y2) as evidenced by the results of the Critical Ratio test $(6,097>1.96)$.

3. Destination image variable (Y2) has a positive and significant effect on Tourist satisfaction (Y3) as evidenced by the results of the Critical Ratio test (7,729>1.96).

4. The tourist satisfaction variable (Y3) has a positive and significant effect on Tourist Loyalty (Y4) as evidenced by the results of the Critical Ratio test $(12,606>1.96)$.

The results of testing this hypothesis, show conformity with the results of research Wilson, et al (2012); Zhang, et al (2014); Lin and Liu, (2018) where they argue that the variable internal motivation determines more tourist decisions to determine tourist destinations. The results of this study are the same as those of Zhang, et al (2014) who found that internal motivation or expectation variables did not have a significant effect directly on tourist satisfaction, nor on tourist loyalty, and had to be mediated by destination image. The same opinion was conveyed by Diarta, et al (2015) that internal motivation is the driving factor before someone goes on a tour.

Furthermore, it is said that motivation is a very basic thing in the study of tourists and tourism because motivation is the driving force of the tour travel process. Likewise, Wilson, et al (2012) argues that internal motivation is the driving factor of a tourist, and external motivation is a pull factor derived from the attributes of a destination. Both Diarta, et al (2015) and Zhang, et al (2014) assume that internal motivation and attractiveness are a unity of interest and motive for someone to travel and at the same time directing where they will travel. So, it can be concluded that the results of testing this hypothesis have strengthened the opinion of Diarta, et al (2015) and Zhang, et al (2014) who argue that internal motivation has a more significant effect on moving someone to travel.

The biggest direct effect is the direct effect between $\left(\mathrm{Y}_{1}\right)$ destination image on $\left(\mathrm{Y}_{2}\right)$ tourist satisfaction with a weight of 1.359 when compared to the direct effect between $\left(\mathrm{Y}_{3}\right)$ tourist satisfaction on $\left(\mathrm{Y}_{4}\right)$ tourist loyalty with a weight of 0.700 , the direct influence between $\left(\mathrm{Y}_{1}\right)$ the attractiveness of the destination to $\left(\mathrm{Y}_{2}\right)$ the destination image with a weight of 0.646 , and the direct influence between $\left(\mathrm{X}_{1}\right)$ tourist expectations (internal motivation) towards $\left(\mathrm{Y}_{1}\right)$ the attractiveness of the destination with a weight of 0.453 ( See Table 9).

Table 9. Direct Effects

\begin{tabular}{lccccc}
\hline Direct Effects & X1 (Expectation) & Y1 (Attraction) & Y2 (Image) & Y3 (Satisfaction) & Y4 (Loyalty) \\
\hline Y1 (Attraction) & 0.453 & 0.000 & 0.000 & 0.000 & 0.000 \\
Y2 (Image) & 0.000 & 0.646 & 0.000 & 0.000 & 0.000 \\
Y3 (Satisfaction) & 0.000 & 0.000 & 1.359 & 0.000 & 0.000 \\
Y4 (Loyalty) & 0.000 & 0.000 & 0.000 & 0.700 & 0.000 \\
\hline
\end{tabular}

\section{Conclusions and Recommendations}

The conclusion is tourist expectation has a positive and significant effect on destination attractiveness. Destination attractiveness has a positive and significant effect on destination image. Destination image has a positive and significant effect on tourist satisfaction. Tourist satisfaction has a positive and significant effect on tourist loyalty in line with previous research by Wilson, et al (2012); Zhang, et al (2014); Utama (2016); Lin and Liu, (2018); Trimurti and Utama (2019).

Although this study reached a large sample size, namely 413 respondents, respondents were dominated by those from Australia so that the results of this study were not representative so they could be used as a reference for generalizing demographic factors and tourist psychographic. The results of the analysis of the confirmation of the suitability of the theoretical model proved to be inadequate to the criteria for conformance with empirical data, which means that the researchers' assumptions about the suitability of the measurement model under study were not 
supported by survey data in the field. The mismatch of theoretical models with survey data is caused by (1) selection of research indicators that are fewer representatives of their latent variables, and (2) several indicators overlap each other so that it is difficult for respondents to distinguish between answers and provide answers.

The theoretical implications of this research are (1) further research can be done that considers respondents from various demographic and psychographic factors. (2) Further research by doing mixed methods. (3) The need to involve respondents from populations that have characteristics as populations that can be selected as a random sample. (4) Subsequent research uses research indicators that can measure indicators directly related to expectations and offers for tourists (Utama and Trimurti, 2019).

The practical implications of this research are based on the results of research that have gaps between theory and data in the field. If Bali tourism destinations, expect tourists to be loyal to Bali destinations, it has implications for maintaining the satisfaction factor of tourists, where at present they are very satisfied with the existing tourist attractions and satisfied with the trip in Bali. Some are also satisfied with the availability of facilities and are satisfied with services during a vacation in Bali.

\section{Acknowledgments}

Thank you to the Ministry Research and Technology the Ministry of Research and Technology for funding the Basic Research Grant in the fiscal year 2019-2020. This study also non-financial has been supported by Lecturers and Students of Universitas Dhyana Pura, Bali.

\section{References}

2. Ahmed, S., \& Rahman, M. (2015). The effects of marketing mix on consumer satisfaction: A literature review from Islamic perspective. Turkish Journal of Islamic Economics, 2(1), 17-30.

3. Arli, D., Tan, L. P., Tjiptono, F., \& Yang, L. (2018). Exploring consumers' purchase intention towards green products in an emerging market: The role of consumers' perceived readiness. International journal of consumer studies, 42(4), 389-401.

4. Armstrong, G., Adam, S., Denize, S., \& Kotler, P. (2014). Principles of marketing. Pearson Australia.

5. Astuti, N. N. S., Ginaya, G., \& Susyarini, N. P. W. A. (2019). Designing Bali tourism model through the implementation of tri hita Karana and sad kertih values. International journal of linguistics, literature, and culture, 5(1), 12-23.

6. Buchanan-Oliver, M., \& Fitzgerald, E. M. (2016). Industry and agency views of social media: Issues implementing dialogic communication. Journal of Marketing Communications, 22(4), 437-454.

7. Chen, C. M., Chen, S. H., \& Lee, H. T. (2011). The destination competitiveness of Kinmen's tourism industry: exploring the interrelationships between tourist perceptions, service performance, customer satisfaction, and sustainable tourism. Journal of Sustainable Tourism, 19(2), 247-264.

8. Cherifi, B., Smith, A., Maitland, R., \& Stevenson, N. (2014). Destination images of non-visitors. Annals of Tourism Research, 49, 190-202.

9. Chernev, A. (2020). The marketing plan handbook. Cerebellum Press.

10. Chi, H. K., Huang, K. C., \& Nguyen, H. M. (2020). Elements of destination brand equity and destination familiarity regarding travel intention. Journal of Retailing and Consumer Services, 52.

11. Crockett, S. A. (2012). A five-step guide to conducting SEM analysis in counseling research. Counseling Outcome Research and Evaluation, 3(1), 30-47.

12. Della Corte, V., Sciarelli, M., Cascella, C., \& Del Gaudio, G. (2015). Customer satisfaction in tourist destinations: The case of tourism offered in the city of Naples. Journal of Investment and Management, 4(11), 39-50.

13. Diarta, I. K. S., Pitana, I. G., Putra, N. D., \& Wiranatha, A. S. (2015). Factors influencing brand equity of Bali as a tourism destination. E-Journal of Tourism, 2(2), 100-112.

14. Hair Jr, J. F., Matthews, L. M., Matthews, R. L., \& Sarstedt, M. (2017). PLS-SEM or CB-SEM: updated guidelines on which method to use. International Journal of Multivariate Data Analysis, 1(2), 107-123.

15. Han, H. (2015). Travelers' pro-environmental behavior in a green lodging context: Converging value-beliefnorm theory and the theory of planned behavior. Tourism Management, 47, 164-177.

16. Kotler, P., Kartajaya, H., \& Hooi, D. H. (2019). Asian competitors: Marketing for competitiveness in the age of digital consumers. World Scientific.

17. Lee, S., Jeon, S., \& Kim, D. (2011). The impact of tour quality and tourist satisfaction on tourist loyalty: The case of Chinese tourists in Korea. Tourism Management, 32(5), 1115-1124. 
18. Li, G., Yang, X., Liu, Q., \& Zheng, F. (2014). Destination island effects: A theoretical framework for the environmental impact assessment of human tourism activities. Tourism Management Perspectives, 10, 1118.

19. Lin, Y. C., \& Liu, Y. C. (2018). Deconstructing the internal structure of perceived authenticity for heritage tourism. Journal of Sustainable Tourism, 26(12), 2134-2152.

20. Park, E., Choi, B. K., \& Lee, T. J. (2019). The role and dimensions of authenticity in heritage tourism. Tourism Management, 74, 99-109.

21. Prebensen, N. K., Woo, E., Chen, J. S., \& Uysal, M. (2013). Motivation and involvement as antecedents of the perceived value of the destination experience. Journal of travel research, 52(2), 253-264.

22. Rajesh, R. (2013). Impact of tourist perceptions, destination image, and tourist satisfaction on destination loyalty: A conceptual model. PASOS. Revista de Turismo y Patrimonio Cultural, 11(3), 67-78.

23. Shah, A. (2014). Internal marketing's effects on employee satisfaction, productivity, product quality, consumer satisfaction, and firm performance. American Journal of Management, 14(4), 33.

24. Stewart, D. W. (2015). Why marketers should study public policy. Journal of Public Policy \& Marketing, 34(1), 1-3.

25. Stylos, N., Vassiliadis, C. A., Bellou, V., \& Andronikidis, A. (2016). Destination images, holistic images, and personal normative beliefs: Predictors of intention to revisit a destination. Tourism Management, 53, 4060 .

26. Tabaku, E., \& Zerellari, M. (2015). Brand loyalty and loyalty programs; a literature review. Romanian Economic and Business Review, 10(2), 87.

27. Trimurti, C. P., \& Utama, I. G. B. R. (2020). The Examination Bali Destination Marketing Chain Model Based On Tourist Motivation. International Journal Of Scientific \& Technology Research Volume, 9, 44914495.

28. Utama, I. G. B. R. (2014). The motivation and satisfaction of elderly tourists visiting Bali tourism destination Indonesia. Journal of Economics and Sustainable Development, 5(18), 1700-2222.

29. Utama, I. G. B. R. (2016). Senior tourists' travel selection: A structural model development. Heritage, Culture, and Society: Research agenda and best practices in the hospitality and tourism industry, 267.

30. Utama, I. G. B. R., \& Mahadewi, N. M. E. (2014). Metodologi penelitian pariwisata dan perhotelan: Dilengkapi studi kasus penelitian. Yogyakarta: Andi.

31. Utama, I. G. B. R., Trimurti, C. P., (2019). The Correlation Tourist Attraction with Revisit Intention of Agritourism Pelaga Badung Bali, Indonesia. Petra International Journal of Business Studies (IJBS). VOL 2 NO 2 (2019): DECEMBER 2019, 121-124

32. Wilson, A., Zeithaml, V. A., Bitner, M. J., \& Gremler, D. D. (2012). Services marketing: Integrating customer focus across the firm.

33. Wilson, A., Zeithaml, V. A., Bitner, M. J., \& Gremler, D. D. (2012). Services marketing: Integrating customer focus across the firm.

34. Wu, C. W. (2016). Destination loyalty modeling of global tourism. Journal of Business Research, 69(6), 2213-2219.

35. Zhang, H., Fu, X., Cai, L. A., \& Lu, L. (2014). Destination image and tourist loyalty: A metaanalysis. Tourism Management, 40, 213-223. 